\title{
Pancreatic amylase in chickens fed on soya-bean diets
}

\author{
BY S. LEPKOVSKY, T. KOIKE, * M. SUGIURA, $†$ \\ M. K. DIMICK AND F. FURUTA \\ Department of Poultry Husbandry, University of California, \\ Berkeley, California 94720, USA \\ (Received 16 August 1965-Accepted 22 March 1966)
}

\begin{abstract}
I. The action of raw and heated soya beans on pancreatic function was studied by measuring the amylase activity of the pancreases and intestinal contents of intact chickens and of chickens with ileostomies at fasting and after eating, before and after adaptation to heated and raw soya-bean diets, with a methionine supplement and without. 2. The concentration of amylase in the pancreases of 8-week-old chickens eating raw soya-bean diets was lower than that of those eating heated soya-bean diets. These chickens were deficient in methionine; supplementation of the raw soya-bean diet with methionine greatly increased the levels of amylase in the pancreases of such chickens; supplementation of the heated soya-bean diet with methionine increased the levels of amylase in pancreases to a smaller extent. 3. Methionine was less effective in increasing the amylase levels of the pancreases of $1 \mathrm{r}$-week-old chickens eating raw soya-bean diets, since at this age the deficiency of methionine was much less pronounced. 4. More amylase activity was found in intestinal contents of chickens eating raw soya-bean diets than in those eating heated soya-bean diets. 5. In vitro studies showed that fractions prepared from raw soya beans, all containing high levels of trypsin inhibitors, stabilized amylase activity despite the active proteolysis of other protein substrates in the same amylase-containing mixtures. $6 . \mathrm{CaCl}_{2}$ stabilized amylase activity in vitro in unactivated and activated pancreatic juice as such, and after additions of raw soya beans or their fractions before and after autoclaving. 7. The increased levels of amylase found in the intestinal contents of the chickens eating raw soya beans may represent greater secretion of amylase activity by the pancreas, stabilization of amylase activity by the raw soya bean, or both factors. Interpretation of measurements of amylase activity in the intestinal contents of chickens eating heated or raw soya beans is uncertain. 8. The bearing of this work on current views of the nutritional value of raw and heated soya beans is discussed.
\end{abstract}

Nearly 20 years ago, Chernick, Lepkovksy \& Chaikoff (I948) showed that chickens eating raw soya-bean (RS) diets for varying periods of time had pancreases that were hypertrophied and contained higher levels of proteases than did pancreases from corresponding chickens that had eaten heated soya-bean (HS) diets. It was shown later by Applegarth, Furuta \& Lepkovsky (1964) that the pancreases of chickens ingesting RS diets were depleted of zymogen granules to a greater extent than corresponding pancreases from chickens ingesting HS diets, indicating a greater release of pancreatic enzymes from the pancreas in response to the ingestion of the RS diets. Chemical analysis supported this histological evidence: lower levels of proteases were found in the pancreases of chickens after eating RS diets than in those of chickens after eating HS diets (Applegarth et al. I964).

The intestinal contents of chickens eating HS and RS diets were examined for corroborative evidence for the greater release of pancreatic enzymes from the pancreases of chickens eating RS diets. Such evidence could not be obtained from studies

* Present address: University of Arkansas Medical Center, Little Rock, Arkansas, USA.

$\uparrow$ Present address: Gifu College of Pharmacy, Gifu, Japan. 
of proteases of intestinal contents, since unknown amounts of proteases, entering the intestinal lumen with the pancreatic juice, were inactivated by the trypsin inhibitor of the RS. It was considered more likely that reliable information could be got from values for the amylase content of intestinal contents, since amylase is not inactivated by the trypsin inhibitor of the RS. Preliminary results showed that the amylase levels were higher in the intestinal contents of chickens eating RS diets than in those of chickens eating HS diets, thus presumably corroborating the chemical and histological evidence for an increased secretion of pancreatic enzymes by the pancreases of chickens eating RS diets.

Other observations were made in the course of these studies. In chickens fed on HS diets, the concentration of amylase (amylase activity/g) was highest in the contents of the upper half of the intestine, decreased in the contents of the lower half of the intestine and decreased further in the caecal and colonic contents. By contrast, in chickens eating RS diets there was little difference in the amylase activity of the contents of the upper and lower halves of the small intestine, but the amylase activity was increased in the caecal and colonic contents. The findings were interpreted to mean that the low amylase activity of the caecal and colonic contents of the chickens fed on the HS diets was due to instability, destruction by intestinal bacteria, or both. The high amylase activity found in the caecal and colonic contents of the chickens fed on the RS diets could have been due to the accumulation of amylase from excessive secretion of the pancreas, the stabilization of amylase by the RS, or the synthesis of amylase by intestinal bacteria.

The pancreatic enzymes were measured in germ-free and conventional chickens (Lepkovsky, Wagner, Furuta, Ozone \& Koike, I964). Little difference was seen in the amylase activity of the contents of the small intestine, caecums and colon between germ-free and conventional chickens, which suggested that there are other causes for the loss of amylase activity.

The use of an ileostomy (Lepkovsky, Furuta, Koike, Hasegawa, Dimick, Krause \& Barnes, 1965) permitted the collection of intestinal contents uncontaminated by caecal contents by short-circuiting of the caecums and colon. It made possible the collection of the total pancreatic juice secreted into the intestine for any given period of time by collecting quantitatively the total contents of the small intestine for this time. This required the collection of the intestinal effluent that passed out of the small intestine of the chicken. Through the use of this technique more amylase was collected from chickens eating RS diets than from chickens eating HS diets. This could be due to greater secretion of amylase in response to the ingestion of RS diets or to stabilization of amylase by RS.

The action of RS and HS upon the stability of amylase was tested in vitro. RS stabilized amylase, but HS did not. RS was then separated into eight fractions. All fractions stabilized amylase in pancreatic juice before activation, but only some of these fractions, all possessing potent trypsin inhibitory activity, stabilized amylase after the proteases were activated. Moreover, the findings indicated that these soyabean fractions acted to stabilize amylase by decreasing proteolytic activity, but also in some other way that is not yet clear. It appeared possible that the in vivo measure- 
ments of amylase activity in intestinal contents of chickens eating HS and RS diets may be subject to error by an artifact. They may reflect the effects of RS and HS on the stability of amylase, but not on pancreatic function, an example of the pitfalls (Kon, 1965) that confront nutritional investigators.

This communication deals with amylase in the pancreas and intestinal contents of chickens fed on RS and HS diets with and without methionine before and after adaptation to these diets; intact chickens and chickens with ileostomies were used as test animals. The in vivo studies were supplemented with in vitro studies on the effect of RS and HS on the stability of amylase.

\section{EXPERIMENTAL}

\section{Chickens and procedure}

The chickens used, their management, and the diets used have been described by Lepkovsky et al. (1965).

Expt $\mathrm{x}$. Fifty-five chickens, 5 weeks of age, were transferred from the stock mash to the experimental diets as follows: twenty-five to the HS diet, ten to the HS $+0.5 \%$ methionine diet, ten to the RS diet, ten to the RS+0.5\% methionine diet. After I 8 days all chickens were offered food for 3 h each day for 3 days; food was withheld overnight for approximately $2 \mathrm{I}$ h. From the twenty-five chickens on the HS diet, fifteen were selected and divided into five groups of three chickens each. Of these, one group was kept as the fasting control, one group was fed on the HS diet, one on the HS + methionine diet, one on the RS diet, and one on the RS + methionine diet. The chickens were killed after feeding for $3 \mathrm{~h}$ and autopsies were performed. These chickens will be called the unadapted chickens.

Of the ten chickens fed on each of the three experimental diets, six were selected from each group; three of them were fasted and the other three were fed for $3 \mathrm{~h}$, after which they were killed and autopsies were performed. The pancreases of the three chickens constituting each group were pooled and frozen. Each small intestine was divided into an upper and lower half, and the contents of each half from the three chickens were pooled and frozen. The caecal and colonic contents were similarly treated. All samples were freeze-dried and analysed for amylase. These chickens will be called the adapted chickens.

Expt 2. Intact unadapted and adapted chickens. This experiment was conducted as described for intact unadapted and adapted chickens in Expt I of Lepkovsky et al. $(1965)$. The samples of pancreases and intestinal contents from this experiment were analysed for amylase.

Expt 3. Unadapted and adapted chickens with ileostomies. This experiment was conducted as described by Lepkovsky et al. (1965) (Expt 2. Unadapted and adapted chickens with ileostomies). The samples of pancreases and intestinal contents from this experiment were analysed for amylase. 


\section{Surgical methods}

Ileostomy. The ileostomy was performed as described by Lepkovsky et al. (1965).

Cannulation of pancreatic duct and preparation of pancreatic juice. The large pancreatic duct was cannulated with a polyethylene tube $\mathrm{PE}-50$ which led into a $15 \mathrm{ml}$ plastic container. The plastic container with its pancreatic juice was removed every $8 \mathrm{~h}$ and each time was replaced with an empty plastic container. The pancreatic juice was at once removed from the plastic container that had just been removed from the chicken, frozen and freeze-dried.

Fractionation of soya beans. The main stages in the fractionation are shown in Fig. I. A portion of $\mathrm{I} \mathrm{kg}$ of soya beans defatted with hexane was stirred with $\mathrm{IO}$ l. tap water and kept in the refrigerator overnight. The mixture was filtered on a Buchner funnel using several layers of cheesecloth instead of filter paper. The cloudy filtrate was returned to the filter until clear filtrate was obtained. The filtered material was washed with about Io l. water. The washed residue was frozen and freeze-dried; this was designated Fraction $\mathrm{I}$. The filtrate which, on standing in the refrigerator, yielded some insoluble matter, was centrifuged in the cold at about $5000 \times \mathbf{g}$; the precipitate was designated Fraction 2. The supernatant liquid was brought to $\mathrm{pH}_{4} \cdot 5$ and the precipitate was filtered through paper. The precipitate was washed three times with water and the washings were discarded: the precipitate was designated Fraction 3 . The filtrate was brought to $\mathrm{pH} 3 \cdot 5$. The precipitate that formed was filtered off on filter paper. It was washed three times and the washings were discarded; this precipitate was designated Fraction 4. Ammonium sulphate was added to the filtrate until it contained $50 \%(\mathrm{w} / \mathrm{v})$ ammonium sulphate. After filtration through filter paper the filtrate was discarded. The precipitate was stirred into I l. water and the insoluble fraction was filtered off. The precipitate was taken up in a small volume of water and dialysed, and the dialysed suspension was frozen and freeze-dried (Fraction 5). To the filtrate ammonium sulphate was added to $30 \%(\mathrm{w} / \mathrm{v})$ concentration. The precipitate was collected by filtration and dialysed. The insoluble material was filtered off, frozen and freeze-dried (Fraction 6). The dialysed filtrate was frozen and freezedried (Fraction 7). The $30 \%$ ammonium sulphate filtrate was made up to $40 \%(\mathrm{w} / \mathrm{v})$ ammonium sulphate and filtered. The filtrate was discarded. The precipitate was dialysed, frozen and freeze-dried (Fraction 8).

\section{Stabilization of amylase by soya bean or its fractions}

Unactivated juice. Freeze-dried chicken pancreatic juice collected as described above was homogenized with cold water $(2.5 \mathrm{mg} / \mathrm{ml})$ in a glass homogenizer and kept at $3^{\circ}$. The soya beans or fractions, heated or unheated $(2 \cdot 5 \mathrm{mg})$, were homogenized with $\mathrm{I} \mathrm{ml}$ of the suspension of pancreatic juice. Amylase activity was determined on these mixtures immediately and after they had been kept in the refrigerator for 5 or 6 days.

Activated pancreatic juice. Pancreatic juice or mixtures of pancreatic juice and HS, RS or one of its fractions were prepared as described above and activated as follows: to $2.0 \mathrm{ml}$ of each of the mixtures containing pancreatic juice were added $2.0 \mathrm{ml}$ water, 
$2.0 \mathrm{ml}$ ०. I M-phosphate buffer, $\mathrm{pH} 5.6$, and $4.0 \mathrm{ml}$ of $0.5 \%$ enterokinase solution (Nutritional Biochemicals Corp., Cleveland, Ohio); the mixtures were incubated at $3^{\circ}$ for $\mathrm{i} \mathrm{h}$, after which $10.0 \mathrm{ml}$ water were added to retain the $\mathrm{pH}$ at 5.6 . Amylase

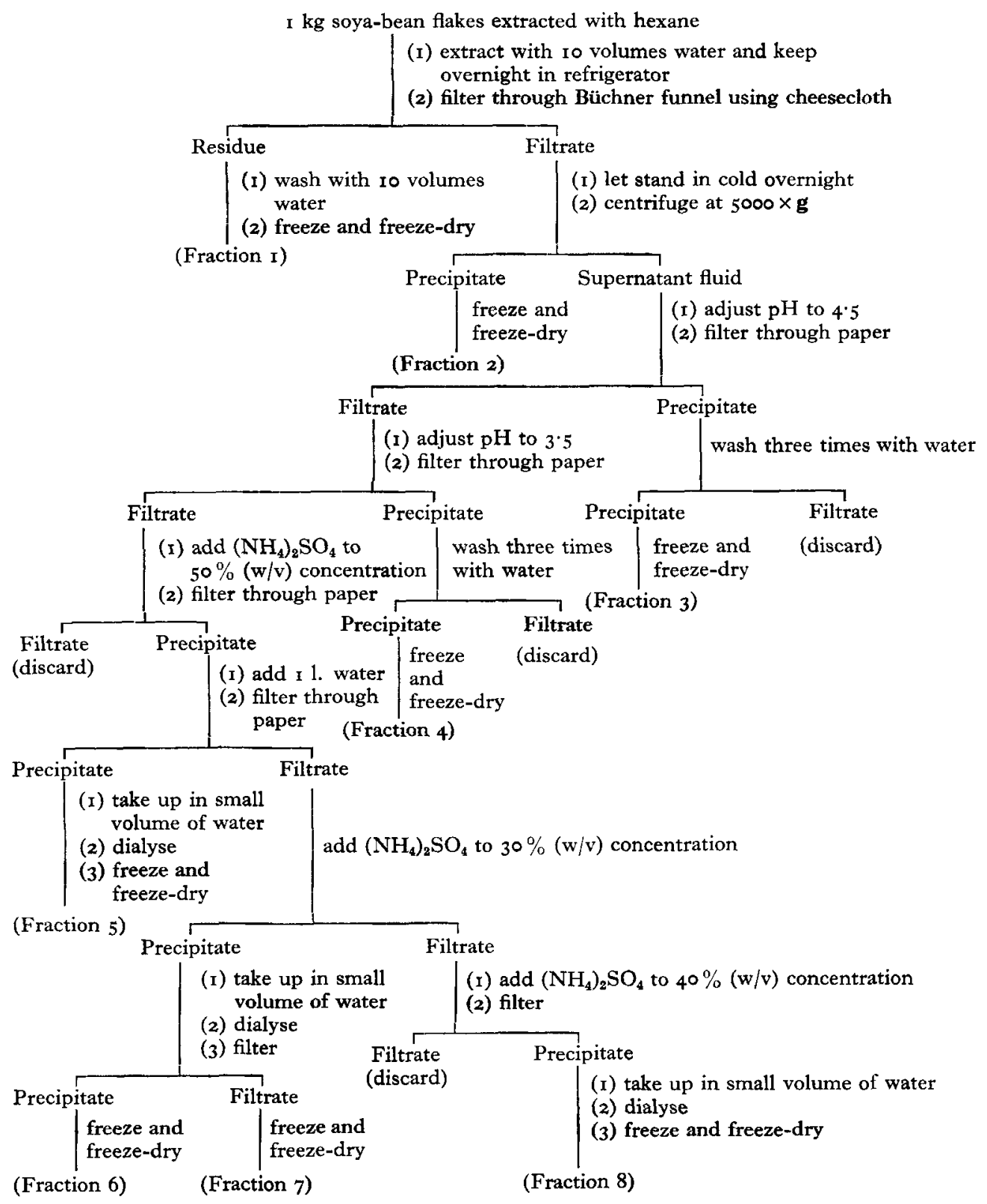

Fig. I. Flow sheet for the fractionation of unheated soya-bean flakes.

activity was determined on these mixtures immediately after mixing and after they had been kept in the refrigerator for 5 or 6 days. At times protease activity in these mixtures was also measured at the end of the storage period in the refrigerator. 


\section{Proteolysis and the stability of amylase}

HS, RS or one of the raw soya-bean fractions was added to the pancreatic juice and homogenized. The pancreatic juice was then activated as described above. After activation the $10 \mathrm{ml}$ of water as used above was replaced by $7 \mathrm{ml}$ of water and $3 \mathrm{ml}$ of suspensions of one of two protein substrates $(20 \mathrm{mg} / \mathrm{ml})$, casein or soya-bean protein. The soya-bean protein was Fraction 3 , as described on p. 424. The soya-bean protein suspension was autoclaved at $15 \mathrm{lb}$ per in ${ }^{2}$ for $15 \mathrm{~min}$ to destroy the residual trypsin inhibitors. Immediately after the addition of the protein substrates, amylase activities, total nitrogen and non-protein nitrogen of the mixtures were measured. The mixtures were stored in the refrigerator for 6 days and the determinations were repeated. The extent of proteolysis was estimated by the increase in non-protein nitrogen.

Total nitrogen was measured in the mixtures described in the previous paragraph by the micro-Kjeldahl method. Non-protein nitrogen was determined as follows: $2 \mathrm{ml} 10 \%$ (w/v) trichloroacetic acid were added to $2 \mathrm{ml}$ portions of the mixtures to precipitate the proteins. After standing for $30 \mathrm{~min}$, the solutions were passed through filter paper. Non-protein nitrogen was determined on the filtrate by the microKjeldahl method. Proteolysis was measured by the increase in non-protein nitrogen calculated by subtracting the value for non-protein nitrogen obtained on the mixtures immediately after preparing them from that obtained after standing for 6 days in the refrigerator.

The action of $\mathrm{CaCl}_{2}$ on the stability of amylase activity in chicken pancreatic juice was determined by adding $\mathrm{CaCl}_{2}(0 \cdot 10 \%$, w/v) to mixtures of pancreatic juice (unactivated and activated) and HS, RS or RS fractions as described above.

Amylase was determined using a starch substrate prepared by the method of McCready \& Hassid (1943); the incubation was carried out by the method of Smith $\&$ Roe (1949). The starch-iodide colour was read in a spectrophotometer (Bausch \& Lomb Spectronic 20) at a wave-length of $650 \mathrm{~nm}$ after setting the instrument at $100 \%$ transmittance with distilled water.

\section{RESULTS}

\section{Intact chickens}

Observations on body-weights and on the pancreases of intact chickens offered the experimental diets for 3 weeks (Expt I) and 6 weeks (Expt 2 ) are shown in Table I. In Table 2 are shown the observations on the intestinal contents.

\section{Weights of intact chickens fed on HS and RS diets}

The weights of the chickens fed on the RS diets for 3 weeks ( 8 weeks of age) were below those of the chickens fed on the HS diet. Methionine increased the weights of the chickens eating HS or RS diets; the increase was greater in the chickens fed on the RS diet. This indicated that both the HS and RS diets were deficient in methionine, but the deficiency was more pronounced in the chickens eating RS diets.

In chickens fed on the experimental diets for 6 weeks (I I weeks of age) the effect 
Vol. 20

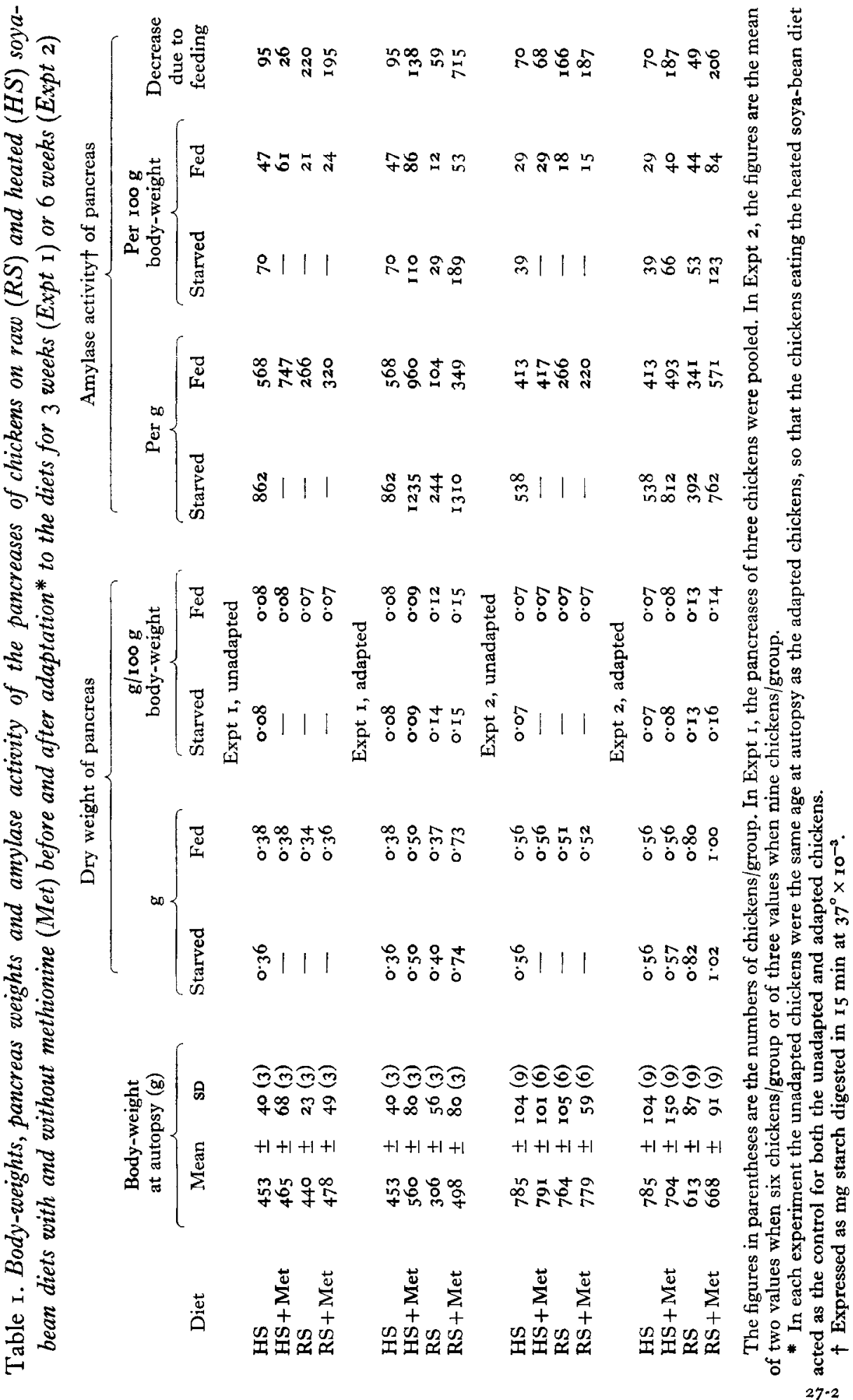




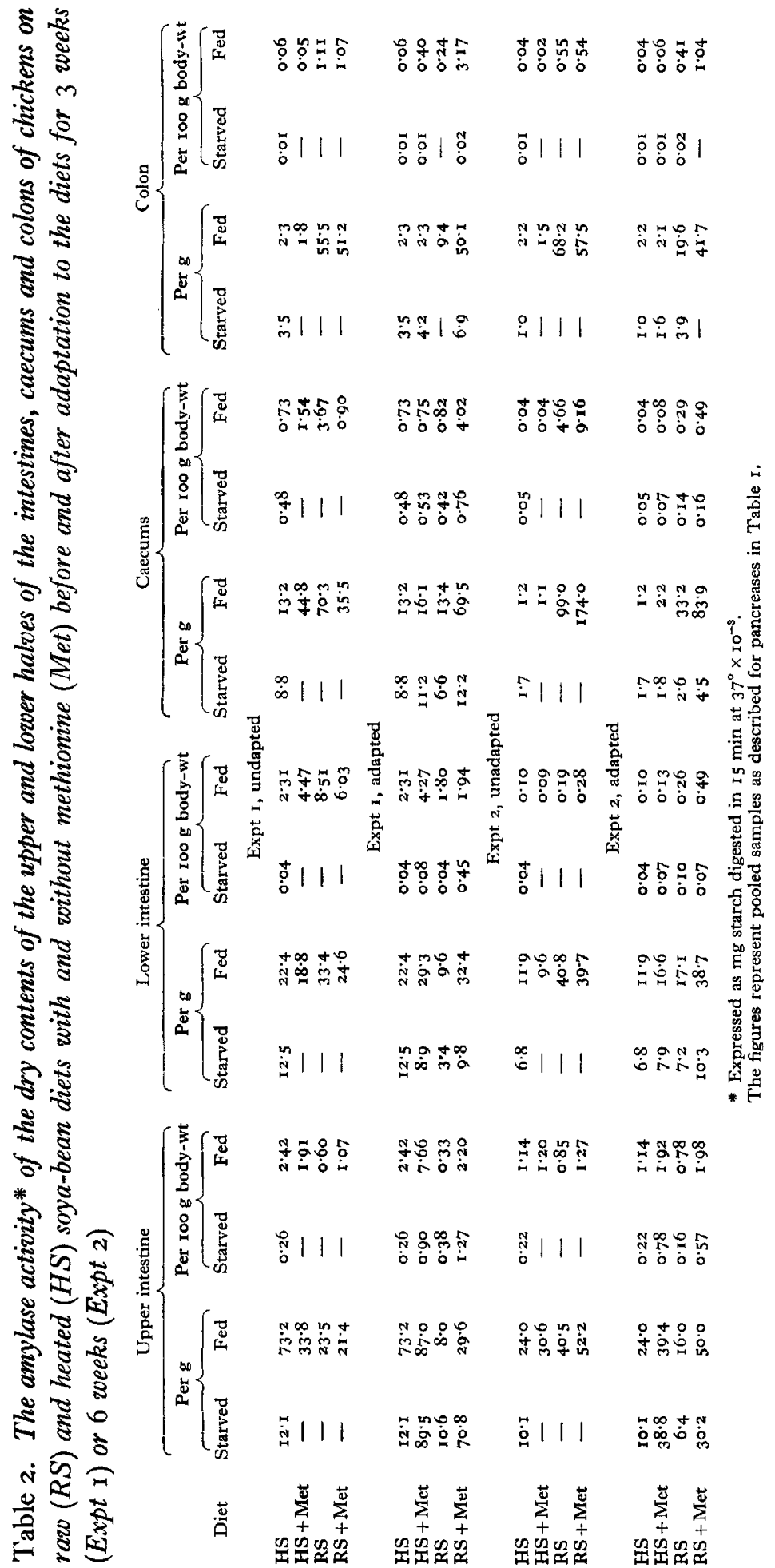


of methionine was much less pronounced. At I I weeks of age, the methionine requirements had decreased so that the amount of methionine in the food was more nearly adequate. This is in agreement with the work of Bornstein \& Lipstein (1963).

\section{Pancreas}

Hyperaemia of the pancreas. At autopsy, the pancreases of chickens eating RS diets almost always appeared pinkish, indicating an increased rate of flow of blood. By comparison, the pancreases of chickens eating HS diets were pale.

The pancreases of the chickens fed on RS diets for either 3 or 6 weeks were heavier, per $100 \mathrm{~g}$ body-weight, than those of the chickens fed on the HS diets.

Amylase levels in the pancreases of starved chickens. Amylase levels in the pancreases of chickens adapted on RS diets for 3 weeks were lower than those in the pancreases of the chickens fed on HS diets (Table I). There were little differences in amylase levels of pancreases of chickens adapted to HS or RS diets when they were supplemented with methionine. Methionine deficiency was associated with low levels of amylase in the pancreas of chickens eating RS diets.

After the chickens had been adapted to the experimental diets for 6 weeks, the amylase levels (activity/g) of the pancreases of the chickens on the RS diet were little different from those of the chickens eating the HS diet. The increases of amylase activity resulting from methionine supplementation of the HS diets were moderate; the increases were greater in chickens eating RS diet.

Decrease in amylase activity in the pancreas in response to eating. The decreases in amylase levels in the pancreases of 8- and I I-week-old chickens eating one meal of RS diet (unadapted chickens) were greater than those of similar chickens eating the HS diet. Methionine had little effect upon the amylase levels in any of these chickens.

After the chickens had been adapted to the experimental diets for 3 or 6 weeks, the decreases of the amylase activity in the pancreases in response to eating reflected the amount of amylase in the pancreases of the chickens at fasting. The pancreases of chickens eating the RS diet contained the lowest levels of amylase at fasting, and the decreases were the least after eating. The decreases were greater with the chickens eating HS diets or RS diets plus methionine (Table I).

\section{Amylase in contents of small intestine, caecums and colon}

The amylase activity of the contents of the small intestines and caecums of the unadapted chickens in Expt I (Table 2) was erratic. The values did not reflect the amounts of enzymes that were apparently secreted by the pancreas into the intestinal lumen. In the colonic contents the expected result was obtained; the amylase levels were much higher in chickens eating RS diets.

After adaptation to the experimental diets, the amylase levels of the contents of the small intestines reflected those of the pancreases. The lowest levels of amylase (activity/g) were found in the contents of the small intestines of the chickens eating RS diet; methionine supplementation greatly increased these amylase levels. The results were more consistent in Expt 2 (Table 2). Before adaptation, the amylase values (activity/g) in the contents of the upper halves of the intestines of the chickens fed 


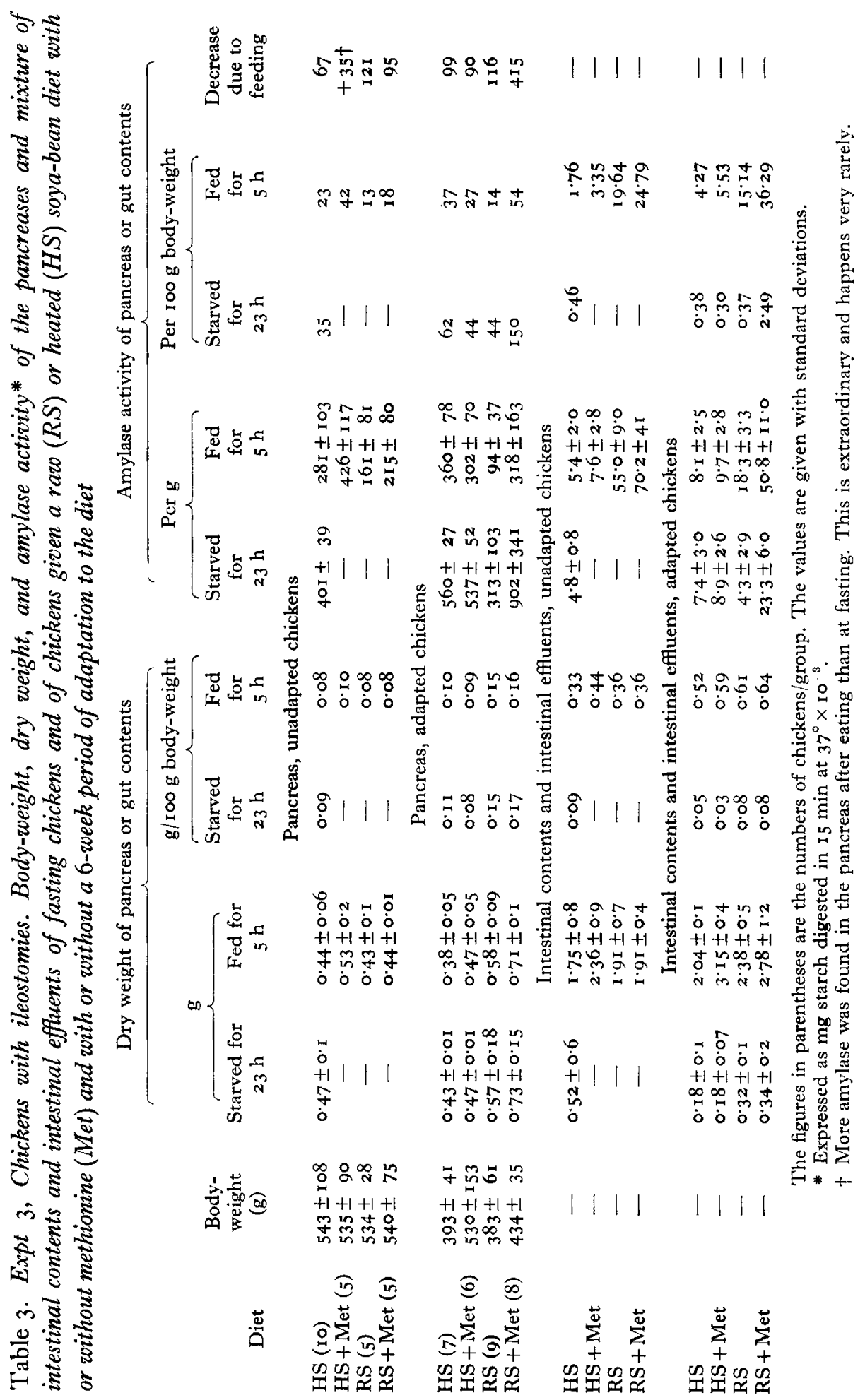


on the RS diets were higher than in those of the chickens fed on the HS diets. This reflected the larger decrease in the amount of amylase in the pancreas (Table r). Methionine had little effect. The amylase activities of the contents of the lower halves of the intestines of the chickens fed on the HS diets decreased, and amylase activity dropped sharply in the caecal and colonic contents. In the chickens fed on the RS diets, the amylase activity of the contents of the lower halves of the small intestines changed little and increased in the caecal and colonic contents.

After adaptation, the amylase activities were lowest in the contents of the upper halves of the small intestines of the chickens fed on the RS diet and were highest in those fed on the same diet plus methionine; these values reflected the decreases in amylase activities of the pancreas in response to eating. The amylase values in the contents of the lower halves of the small intestines of the chickens fed on the HS diets decreased from that in the upper halves and dropped markedly in the caecal and colonic contents. The amylase values in the contents of the lower halves of the small intestines of the chickens fed on the RS diets changed little from those found in the upper halves, and increased in the caecal contents. The amylase activity of the colonic contents resembled that of the contents of the lower halves of the small intestines.

Table 4. Stability of amylase in unactivated or activated pancreatic juice, fresh or stored in the refrigerator for 6 or 8 days, in the presence of soya beans $(R S)$ or heated soya beans $(H S)$ or of the fractions of raw soya beans

\begin{tabular}{|c|c|c|c|c|c|c|c|}
\hline \multirow{4}{*}{$\begin{array}{l}\text { Addition } \\
\text { to } \\
\text { pancreatic } \\
\text { juice }\end{array}$} & \multicolumn{6}{|c|}{ Amylase activity* } & \multirow{4}{*}{$\begin{array}{c}\text { Protease } \\
\text { activity } \\
\text { in } \\
\text { activated } \\
\text { pancreatic } \\
\text { juice } \\
\text { RS or } \\
\text { fractions } \\
\text { Stored } \\
8 \text { days }\end{array}$} \\
\hline & \multicolumn{4}{|c|}{ Unactivated $\dagger$ pancreatic juice } & \multirow{2}{*}{\multicolumn{2}{|c|}{$\begin{array}{c}\text { Activated } \dagger \\
\text { pancreatic juice } \\
\text { RS or fractions }\end{array}$}} & \\
\hline & \multicolumn{2}{|c|}{ RS or fractions } & \multicolumn{2}{|c|}{ HS or heated fractions } & & & \\
\hline & Fresh & $\begin{array}{l}\text { Stored } \\
6 \text { days }\end{array}$ & Fresh & $\begin{array}{l}\text { Stored } \\
6 \text { days }\end{array}$ & Fresh & $\begin{array}{l}\text { Stored } \\
6 \text { days }\end{array}$ & \\
\hline Soya beans & 2744 & $2396 \pm 19$ & 2744 & $1038 \pm 113$ & $2288 \pm 39$ & $578 \pm 244$ & $20 \cdot 56$ \\
\hline Fraction 1 & $2760 \pm 188$ & $2640 \pm 163$ & $2669 \pm 39$ & 2333 & $1566 \pm 1066$ & 275 & - \\
\hline Fraction 2 & $2736 \pm 6 r$ & $2893 \pm 82$ & $2714 \pm 88$ & $1709 \pm 828$ & 2500 & $275 \pm 71$ & - \\
\hline Fraction 3 & $2304 \pm 27$ & $2386 \pm 78$ & $2304 \pm 27$ & $2368 \pm 48$ & $2272 \pm 0$ & $2024 \pm 48$ & $16 \cdot 37 \pm 4 \cdot 9$ \\
\hline Fraction 4 & $2304 \pm 27$ & $2384 \pm 55$ & $2288 \pm 27$ & $2240 \pm 39$ & $2284 \pm 55$ & $2450 \pm 104$ & $13.58 \pm 4.9$ \\
\hline Fraction 5 & $2304 \pm 27$ & $2202 \pm 60$ & $2304 \pm 27$ & $2320 \pm 48$ & $2240 \pm 32$ & $2320 \pm 48$ & I I. $85 \pm 5 \cdot 2$ \\
\hline Fraction 6 & $2304 \pm 27$ & $2336 \pm 55$ & $2288 \pm 27$ & $2368 \pm 48$ & $2304 \pm 27$ & $2368 \pm 48$ & $7 \cdot 78 \pm 3 \cdot 4$ \\
\hline Fraction 7 & $2288 \pm 27$ & $2368 \pm 48$ & $2304 \pm 27$ & $2375 \pm 27$ & $2272 \pm 0$ & $2437 \pm 60$ & $5 \cdot 92 \pm 2 \cdot 7$ \\
\hline Fraction 8 & $2605 \pm 26$ & $2584 \pm 224$ & $2605 \pm 80$ & $1765 \pm 523$ & - & - & \\
\hline
\end{tabular}

Mean values and standard deviations for three analyses/group, except six analyses/group for the soyabean group.

* Expressed as mg starch digested in $15 \mathrm{~min}$ at $37^{\circ} \times 10^{-3}$.

$\uparrow$ Amylase activity in inactivated pancreatic juice stored in the refrigerator for $\mathbf{5}$ days decreased in activity from 2744 to $1594 \pm 24$. Amylase activity in activated pancreatic juice under these conditions decreased from 2664 to $14 \mathrm{I} \pm 8$.

$\ddagger$ Expressed as m-equiv, tyrosine released in Io $\min$ at $37^{\circ}$ per $\mathrm{g}$ dry pancreatic juice. 


\section{Chickens with ileostomies}

In general, the results for the pancreases of chickens with ileostomies agreed with those obtained with intact chickens in their responses to HS and RS diets. The amylase content of the pancreases of chickens given one meal of HS diet plus methionine (Table 3 ) was higher than that of the fasted controls. The amylase activity of the intestinal contents obtained from chickens with ileostomies fed on RS diets was higher than that obtained from chickens fed on HS diets. Supplementation of the RS diet with methionine caused little increase in the amylase activity of the intestinal contents of the unadapted chickens but the increase was much greater in those of the adapted chickens (Table 3).

Table 5. Stabilizing activity of $\mathrm{CaCl}_{2}$ on amylase activity in pancreatic juice

\begin{tabular}{|c|c|c|c|c|c|c|}
\hline \multirow{3}{*}{$\begin{array}{c}\text { Addition to } \\
\text { pancreatic juice }\end{array}$} & & & \multicolumn{4}{|c|}{ After 7 days in refrigerator } \\
\hline & \multicolumn{2}{|c|}{ Initial activity } & \multicolumn{2}{|c|}{ No $\mathrm{CaCl}_{2}$} & \multicolumn{2}{|c|}{$0 . \mathrm{I} \%(\mathrm{w} / \mathrm{v}) \mathrm{CaCl}_{2} *$} \\
\hline & Unactivated & Activated & Unactivated & Activated & Unactivated & Activated \\
\hline None & $\begin{array}{l}3470 \\
2760 \\
2590\end{array}$ & $\begin{array}{l}3379 \\
3144 \\
2499\end{array}$ & $\begin{array}{r}891 \\
2000 \\
2363\end{array}$ & $\begin{array}{l}46 \\
76 \\
91\end{array}$ & $\begin{array}{l}3653 \\
3192 \\
2408\end{array}$ & $\begin{array}{l}3470 \\
3288 \\
2090\end{array}$ \\
\hline HS & $\begin{array}{l}3379 \\
2664 \\
2590\end{array}$ & $\begin{array}{l}3196 \\
3144 \\
2636\end{array}$ & $\begin{array}{r}1005 \\
81 \\
218\end{array}$ & $\begin{array}{r}74 \\
102 \\
136\end{array}$ & $\begin{array}{l}3607 \\
3144 \\
2317\end{array}$ & $\begin{array}{l}35 \text { I6 } \\
3336 \\
2363\end{array}$ \\
\hline RS & $\begin{array}{l}3470 \\
2568 \\
2636\end{array}$ & $\begin{array}{l}3379 \\
3144 \\
2636\end{array}$ & $\begin{array}{l}3288 \\
2808 \\
2408\end{array}$ & $\begin{array}{r}776 \\
1096 \\
682\end{array}$ & $\begin{array}{l}3744 \\
3144 \\
2590\end{array}$ & $\begin{array}{l}3^{6} 53 \\
3472 \\
2590\end{array}$ \\
\hline Fraction 5 & 3470 & 3288 & 3562 & 685 & 3607 & 3653 \\
\hline Fraction 6 & $\begin{array}{l}3288 \\
2856 \\
2636\end{array}$ & $\begin{array}{l}3288 \\
3048 \\
2636\end{array}$ & $\begin{array}{l}3836 \\
3096 \\
263^{6}\end{array}$ & $\begin{array}{r}639 \\
3288 \\
2590\end{array}$ & $\begin{array}{l}3744 \\
3424 \\
2681\end{array}$ & $\begin{array}{l}3653 \\
3616 \\
28 \times 7\end{array}$ \\
\hline Fraction 7 & 3470 & 3379 & 3653 & 685 & 3607 & 3562 \\
\hline Fraction 5 (heated) $\dagger$ & 3470 & 3470 & 1370 & 445 & 3562 & 3562 \\
\hline Fraction 6 (heated) $†$ & $\begin{array}{l}3288 \\
2760 \\
2545\end{array}$ & $\begin{array}{l}3288 \\
3048 \\
2545\end{array}$ & $\begin{array}{l}3653 \\
2808 \\
2545\end{array}$ & $\begin{array}{l}548 \\
32 I \\
409\end{array}$ & $\begin{array}{l}3653 \\
3240 \\
2499\end{array}$ & $\begin{array}{l}3744 \\
3424 \\
2636\end{array}$ \\
\hline Fraction 7 (heated) $\uparrow$ & $347^{\circ}$ & $347^{\circ}$ & 3288 & 343 & 3562 & 3607 \\
\hline
\end{tabular}

* $\mathrm{CaCl}_{2}$ stabilized amylase activity in chicken pancreatic juice in concentrations as low as $0.005^{-}$ $0.01 \%(\mathrm{w} / \mathrm{v})(0.05-0.1 \mathrm{mg} / \mathrm{ml})$.

+ Fractions 5,6 and $7(2.5 \mathrm{mg} / \mathrm{ml})$ were autoclaved at ${ }_{5}$ lb per in ${ }^{2}$ for ${ }_{5} \mathrm{~min}$ to destroy the trypsin inhibitors.

\section{Stability of amylase activity in pancreatic juice in vitro}

The results are shown in Table 4. They represent the action of RS and its eight fractions before and after autoclaving upon the amylase activity of chicken pancreatic juice, before and after activation by enterokinase $\left(\mathrm{pH}_{5} \cdot 6\right)$.

Unactivated pancreatic juice. The amylase activity of untreated pancreatic juice decreased after 5 or 6 days during storage in the refrigerator (Table 4 ). RS and all of its eight fractions stabilized it under these conditions. After autoclaving, $\mathrm{HS}$ and its 
Vol. 20

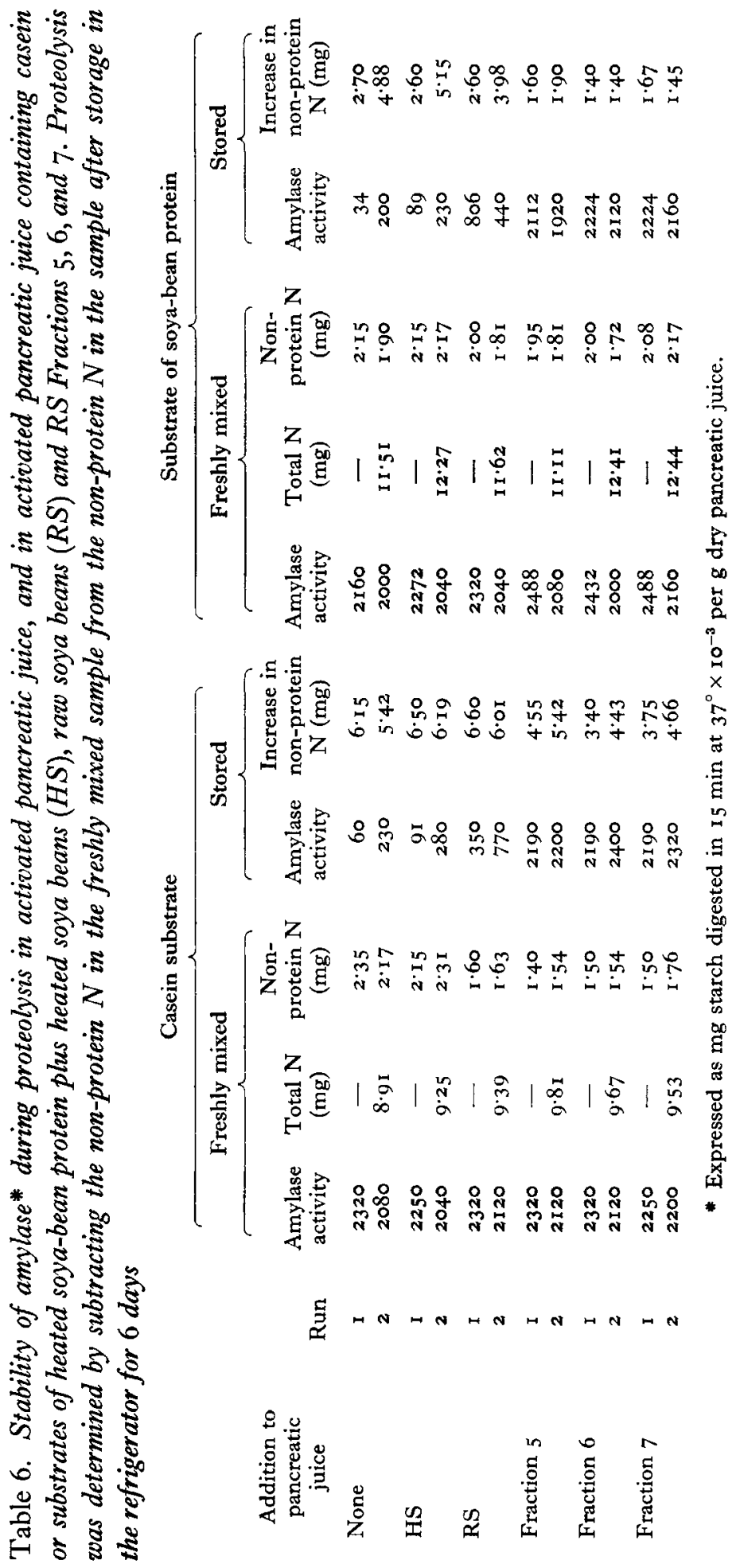


fractions gave erratic results (Table 4). With the exception of Fractions 5, 6 and 7 which stabilized amylase activity, the other fractions did not consistently affect enzyme stability.

Activated pancreatic juice. Amylase activity in activated pancreatic juice was very unstable on storage in the refrigerator (Table 4). Neither HS nor any of the heated soya-bean fractions had any stabilizing action upon amylase activity; of the unheated fractions only Fractions 5, 6 and 7, all containing high trypsin inhibitor activity, stabilized amylase activity (Table 4 ).

$\mathrm{CaCl}_{2}$ and amylase activity. $\mathrm{CaCl}_{2}$ had a marked effect in stabilizing amylase in unactivated and activated chicken pancreatic juice (Table 5 ) before and after additions of $\mathrm{HS}, \mathrm{RS}$, or RS fractions. $\mathrm{CaCl}_{2}$ stabilized amylase activity at a concentration of $\mathrm{I} \cdot 0 \mathrm{mg} / \mathrm{ml}$; it did so in concentrations as low as $0.05-0.1 \mathrm{mg} / \mathrm{ml}$. Table 5 shows some discrepancies from previous measurements. One sample of unactivated pancreatic juice showed no loss of amylase activity after storage for 7 days at refrigerator temperatures. This is the only exception out of a total of fifteen measurements. Table 5 also shows failure in one run to stabilize amylase activity in activated juice by RS Fractions 5, 6 and 7. This occurred once out of some six to nine such measurements. The stability of amylase activity is so sensitive to $\mathrm{CaCl}_{2}$ that it indicates that it may also be sensitive to some other factor, the nature of which is not known.

Proteolysis and amylase stability. The results are shown in Table 6. Two protein substrates were used to measure proteolysis, namely casein and soya-bean proteins. The values show no close correlation between proteolysis and stability of amylase; amylase was not necessarily inactivated while active proteolysis of other proteins was proceeding (Table 6 ).

\section{DISCUSSION}

The pancreases of the chickens responded to the ingestion of RS diets with (I) hyperaemia, (2) decreases of pancreatic enzymes and reduction in numbers of zymogen granules below those in chickens eating HS diets. These observations have led to the assumption that more pancreatic juice is secreted into the intestine in response to the ingestion of RS diets than of HS diets (for review, see Guggenheim \& Goldberg, 1964). This assumption is based on indirect evidence, since no direct evidence has been offered such as measurements on the rate of flow of pancreatic juice into the intestinal lumen or on the composition of the juice.

When 5 -week-old chickens were fed on RS diets for 3 weeks ( 8 weeks of age), the pancreases contained more proteases than did pancreases of chickens eating HS diets (Lepkovsky, unpublished). By contrast, the levels of amylase in these pancreases were below those of the chickens eating HS diets, showing that, in the same pancreas at the same time, the rate of synthesis of one protein, protease, is increased, while that of another protein, amylase, is decreased. Supplementation of the diets with methionine markedly increased the amount of amylase in the pancreases of the chickens eating the RS diets.

Hokin \& Hokin (1959) showed, with slices of pigeon pancreas, that all the essential amino acids except methionine were needed for the synthesis of amylase. This could 
be due to the absence of methionine from the amylase molecule (Meyer, Fischer $\&$ Bernfeld, 1947) or its presence in small amounts (Caldwell, Dickey, Hanrahan, Kung, Kung \& Misko, I954). The in vivo results with the intact chickens do not agree with the in vitro results obtained with slices of pigeon pancreas. Methionine was available to the pancreases of the intact chickens eating the RS diets, since sufficient methionine was present in circulating fluids to support the growth of the chicken, albeit at a reduced rate. It is possible that the synthesis of amylase by the pancreas in the intact chicken involves metabolic reactions that are dependent on methionine.

Amylase activity in the contents of the upper half of the small intestine differed little between those coming from unadapted chickens fed on HS diets and those from chickens fed on RS diets. The amylase activity of the intestinal contents decreased as they moved caudally in chickens eating HS diets. In most instances, the amylase activity of the caecal and colonic contents were but a small fraction of the amylase activity in the contents of the upper half of the small intestine. By contrast, the amylase

Table 7. Total amylase activity of the pancreases of chickens with ileostomies after a $23 h$ fast; comparison of the decrease of the activity of this enzyme in the pancreases of chickens given one 5 feeding of heated soya beans (HS) or raw soya beans (RS) with and without methionine (Met), without and with prior adaptation to them, with the amount of amylase recovered from the contents of the intestine plus that in the intestinal effluents; also amylase found in the $24 \mathrm{~h}$ collections of intestinal effluents

\begin{tabular}{|c|c|c|c|c|}
\hline & \multicolumn{4}{|c|}{ Amylase activity* in } \\
\hline & \multicolumn{2}{|c|}{ Pancreas } & \multirow{2}{*}{$\begin{array}{l}\text { Intestinal } \\
\text { contents }+ \\
\text { intestinal } \\
\text { effluents } \\
\text { after } \\
\text { feeding for } \\
\quad 5 \mathrm{~h}\end{array}$} & \multirow{2}{*}{$\begin{array}{l}\text { Intestinal } \\
\text { effluents } \\
\text { collected } \\
\text { for } 24 \mathrm{~h}\end{array}$} \\
\hline Diet & Fasted $23 \mathrm{~h}$ & $\begin{array}{l}\text { Decrease } \\
\text { after feeding } \\
\text { for } 5 \mathrm{~h}\end{array}$ & & \\
\hline \multicolumn{5}{|c|}{ Unadapted } \\
\hline HS & 190.0 & 67.0 & $9 \cdot 4$ & $25 \cdot 1$ \\
\hline $\mathrm{HS}+\mathrm{Met}$ & - & $+35 . \circ \dagger$ & $17 \cdot 9$ & - \\
\hline RS & - & $121 \cdot 0$ & 104.9 & - \\
\hline $\mathrm{RS}+\mathrm{Met}$ & ... & $95^{\circ} \circ$ & 133.9 & - \\
\hline \multicolumn{5}{|c|}{ Adapted } \\
\hline HS & $243^{\circ} 0$ & $99 \cdot 0$ & $16 \cdot 8$ & $26 \cdot 6$ \\
\hline $\mathrm{HS}+\mathrm{Met}$ & $234^{\circ} 0$ & $90 \cdot 0$ & $29 \cdot 3$ & I $8 \cdot 1$ \\
\hline RS & $169^{\circ} 0$ & 116.0 & $44^{\circ} I$ & $175^{\circ} \mathbf{I}$ \\
\hline $\mathrm{RS}+\mathrm{Met}$ & $649 \cdot 0$ & 415.0 & 157.5 & $356 \cdot 6$ \\
\hline
\end{tabular}

activity of intestinal contents of chickens eating RS diets did not decrease as they moved caudally and in some instances increased in the caecal and colonic contents. As a consequence, the intestinal effluents as collected through the ileostomy of chickens eating HS or RS diets reflect the changes in amylase activity in the contents 
of the small intestine as they move caudally in the small intestine. The caecums and colons of these chickens have been eliminated as factors in such chickens by the il eostomy.

A balance sheet was drawn up (Table 7) comparing the amount of pancreatic amylase that was secreted into the intestine during a $5 \mathrm{~h}$ period of feeding with the amounts of amylase recovered by the quantitative collections of the intestinal contents and effluents during this period. The amount of amylase leaving the pancreas was determined by measuring the amount of amylase in the pancreases of the chickens at fasting (when it was at its highest), and subtracting from this value the amount of amylase activity remaining in the pancreases after the chickens were fed. Thus the calculated amounts of amylase leaving the pancreas were minimal values, since no account was taken of the amount of amylase that was synthesized in the pancreas during this period. The amount of amylase collected with the intestinal contents of chickens fed on HS diets was small compared to the calculated amount of amylase that was released from the pancreases of these chickens (Table 7), pointing to extensive inactivation of amylase activity in the intestinal contents.

The amounts of amylase that were recovered with the intestinal contents of the unadapted chickens eating RS diets for $\mathbf{5}$ approximated to the calculated amounts of amylase that were secreted (minimal values) from the pancreases, representing a much better recovery than that obtained with HS diets (Table 7). This did not occur to the same extent in the adapted chickens fed on RS diets.

The $24 \mathrm{~h}$ recoveries of amylase activity from intestinal effluents of adapted chickens eating the HS diets were but a minor fraction of the total amylase activity of the pancreases of the chickens at fasting; by comparison, the $24 \mathrm{~h}$ recoveries of amylase activity from the intestinal effluents of adapted chickens eating the RS diets equalled the amylase activity in the pancreases of the chickens at fasting, or comprised a major fraction of the amylase activity in such pancreases.

The higher values for amylase recovered from the intestinal contents of chickens eating RS diets may be due to: (I) secretion of amylase from the pancreas in amounts sufficiently high to replace that lost through instability or otherwise, plus enough additional amylase to give the higher values observed in chickens eating RS diets; or (2) stabilization of amylase by RS diets; or (3) both.

In vitro studies showed that the RS and all of its eight fractions stabilized the activity of the amylase in unactivated pancreatic juice. Some of the soya-bean fractions rich in trypsin inhibitors stabilized amylase after they had been autoclaved and, therefore, were devoid of trypsin inhibitory activity (Table 4).

Activation of pancreatic juice markedly accelerated the loss of amylase activity. $\mathrm{CaCl}_{2}$ markedly stabilized amylase activity under these conditions (Table 5 ). Some of the soya-bean fractions, notably Fractions 5,6 and 7 , all rich in trypsin inhibitors, stabilized in most instances the amylase activity in activated pancreatic juice (Table 4). After autoclaving neither HS nor any of the eight fractions stabilized the amylase activity in activated pancreatic juice, except where $\mathrm{CaCl}_{2}$ was added and the amylase activity was stabilized (Table 5). As shown in Table 4, the proteolytic activity of the activated pancreatic juice was markedly reduced by Fractions 5,6 and 7 , which raised 
the question whether the reduction in proteolytic activity accounted for the stabilization of the amylase.

The results in Table 6 showed that the soya-bean Fractions 5, 6 and 7 stabilized amylase against proteolysis while casein and soya-bean proteins were undergoing active proteolysis. These findings indicated that the protection afforded to amylase by soya-bean fractions rich in inhibitors was not solely through their action in the reduction of the proteolytic activity of the pancreatic juice; they also seem to stabilize amylase in some other way. This possibility is likely, since heated soya-bean fractions, devoid of trypsin inhibitory activity, stabilized amylase activity in unactivated pancreatic juice (Table 4 ). It is possible that compounds in RS combine with an active group in the amylase molecule, stabilizing it against proteolysis without impairing its activity as an enzyme.

The higher amylase activity in the intestinal, caecal and colonic contents of chickens eating RS diets has been advanced as evidence of excessive secretion of pancreatic juice. The excessive secretion of pancreatic juice in response to RS has been claimed as one of the causes of the lower nutritive value of raw soya beans. This requires further experimental support, if raw soya beans stabilize amylase activity in vivo as they do in vitro, since it is not possible to differentiate between excessive secretion of amylase from the pancreas and the action of RS in stabilizing this enzyme in intestinal, caecal and colonic contents. This study needs to be extended to the other pancreatic enzymes. The reason for the low nutritional value of RS remains to be elucidated.

This research investigation was supported in part by Grant GB-242 from the National Science Foundation and US Public Health Service Grants A-I 804 and A-I 805 from The National Institutes of Health.

\section{REFERENCES}

Applegarth, A., Furuta, F. \& Lepkovsky, S. (1964). Poult. Sci. 43, 733.

Bornstein, S. \& Lipstein, B. (1963). Poult. Sci. 42, 61.

Caldwell, M. L., Dickey, E. S., Hanrahan, V. M., Kung, H. C., Kung, J. T. \& Misko, M. (I954). F. Am. chem. Soc. 76, 143 .

Chernick, S. S., Lepkovsky, S. \& Chaikoff, I. L. (1948). Am. F. Physiol. I55, 33.

Guggenheim, K. \& Goldberg, A. (1964). In The Role of the Gastrointestinal Tract in Protein Metabolism, p. 63. [H. N. Munro, editor.] Oxford: Blackwell Scientific Publications.

Hokin, L. \& Hokin, M. (1959). Gastroenterologia, Basel 36, 368.

Kon, S. K. (1965). Dairy Sci. Abstr. 27, 421.

Lepkovsky, S., Furuta, F., Koike, T., Hasegawa, N., Dimick, M. K., Krause, K. \& Barnes, F. J. (1965). Br. F. Nutr. 19, 41.

Lepkovsky, S., Wagner, M., Furuta, F., Ozone, K. \& Koike, T. (I964). Poult. Sci. 43, 722.

McCready, R. M. \& Hassid, W. Z. (r943). F. Amer. chem. Soc. 65, I 54.

Meyer, K. H., Fischer, E. H. \& Bernfeld, P. (1947). Archs Biochem. 14, 149.

Smith, B. W. \& Roe, J. H. (1949). F. biol. Chem. 179, 53. 